\title{
Insight of teachers on problems of students in acquiring communicative skill in English
}

\begin{abstract}
The study examined the insight of English Teacher towards students of standard XI in acquiring communicative skill in English. The main objective of the paper was to identify the problems of the students in acquiring communicative skill in English. The Normative survey method was adopted in the study. One hundred teachers were considered as a sample for the study. Problem inventory for the teacher was selected as a tool for the study. After establishing Reliability and validity of the tool, it was considered for the final study. Findings of the study is a significant association between the Male and Female teachers on the opinion of problems of the learners in Listening skill with respect to stress pattern, cohesive device, Distinctive sound, Intonation, Contextual meaning and Homophones. Communicative skill can be practiced in the classroom transaction by using role play, pandemonium, discussion, interaction, translated version of Tamil cinema, etc. Written communicative skill can be developed by conducting essay competition, preparing advertisement, preparing projects, etc.
\end{abstract}

Keyword: Communicative skill; Acquisition of English; Error free communication; Skimming and scanning 